mental health issues and their treatment are related to the insufficient cultural integration of the Roma people, especially regarding women's rights issues and education. A lack of sufficient cultural sensitivity in mental health services also plays an important role.

The achievement of equal status between women and men is a very ambitious and timeconsuming aim, and although attempts must be made toward this goal, any results will be very much in the long term. On the other hand, improvement in Roma educational status is an easier goal to achieve, and can help Roma individuals in their integration and, consequently, their mental health status improvement. Adjusting mental health services to their needs is also a much more feasible goal, and can be achieved much sooner.

\section{Author contributions}

T.V., A.A., A.S. and M.S. all contributed to the writing of this paper.

\section{Funding}

None.

\section{Declaration of interest \\ None.}

\section{References}

1 Kalaydjieva L, Calafell F, Jobling MA, Angelicheva D, de Knijff $\mathrm{P}$, Rosser $\mathrm{ZH}$, et al Patterns of inter- and intra-group genetic diversity in the Vlax Roma as revealed by $Y$ chromosome and mitochondrial DNA lineages. Eur J Hum Genet 2001; 9: 97-104.

2 Fraser A. The Gypsies. Blackwell Publishers Ltd., 1992

3 Vivian C, Dundes L. The crossroads of culture and health among the Roma (Gypsies). J Nurs Scholarsh 2004; 36: 86-91.
4 Vorvolakos T, Samakouri M, Xenitidis K, Perentzi M, Tzavaras N, Livaditis M. Reliability and validity of the Greek version of the Derogatis Psychiatric Rating Scale (DPRS). Int J Soc Psychiatry 2006; 52: 501-11.

5 Vorvolakos T, Samakouri M, Tripsianis G, Tsatalmpasidou E, Arvaniti A, Terzoudi A, et al Sociodemographic and clinical characteristics of Roma and non-Roma psychiatric outpatients in Greece. Ethn Health 2012; 17: 161-9.

6 European Roma Rights Centre. Roma Suffer Discrimination in Access to Health Care in Greece. European Roma Rights Centre, 2002 (http://www.errc.org/roma-rights-journal/romasuffer-discrimination-in-access-to-health-care-in-greece)

7 Pappa E, Chatzikonstantinidou S, Chalkiopoulos G, Papadopoulos A, Niakas D. Health-related quality of life of the Roma in Greece: the role of socio-economic characteristics and housing conditions. Int J Environ Res Public Health 2015; 12: 6669-81

8 European Commission. Roma Health Report, Health Status of the Roma Population. Data Collection in the Member States of the European Union. European Union, 2014 (https://ec.europa. eu/health/sites/health/files/social_determinants/docs/ 2014_roma_health_report_en.pdf)

9 World Health Organization. The ICD-10 Classification of Mental and Behavioural Disorders: Clinical Descriptions and Diagnostic Guidelines. World Health Organization, 1992.

10 American Psychiatric Association. Diagnostic and Statistical Manual of Mental Disorders (DSM-5尺). American Psychiatric Publishing, 2013.

11 Vorvolakos T. Psychological Factors and Psychological Manifestations of the Gypsies of Thrace. Democritus University of Thrace, 2006 (www.didaktorika.gr/eadd/handle/10442/ 17620).

12 Lambousis E, Politis A, Markidis M, Christodoulou GN. Development and use of online mental health services in Greece. ] Telemed Telecare 2002: 8. 51-2.

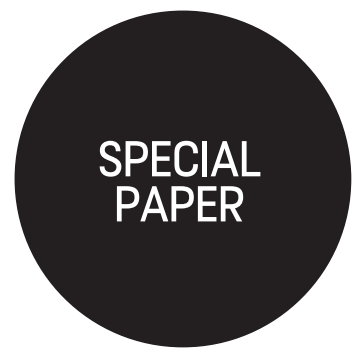

\title{
School bullying and minority identity as a menace to mental well-being of students in Greece
}

\author{
Alexandra Gkouliama, ${ }^{1}$ Maria Samakouri ${ }^{2}$ and Aspasia Serdari ${ }^{1}$ ๑
}

1Department of Child and Adolescent Psychiatry, Medical School, Democritus University of Thrace, Greece. Email: aserntar@ med.duth.gr

${ }^{2}$ Department of Psychiatry, Medical School, Democritus University of Thrace, Greece

A video abstract for this article is available at: https://vimeo.com/ bjpsych/bji-2020-51

Keywords. School bullying; minority; mental health; multicultural; child psychiatry.
Increasing migration and the resultant multiculturalism in Greek society has highlighted the importance of studying the role of school ethnic composition in bullying and peer victimisation, not least because ethnic minority students involved in bullying behaviours seem to experience high levels of internalising and externalising problems. It is imperative that schools work towards ensuring a safe environment for all students. This can be achieved through the implementation of policies that facilitate positive social interactions and address issues of bias-based bullying, thus contributing to social justice. This article examines school bullying and related policies in Greece in the context of increasing diversity and reviews their evolution in the past decade.

School bullying has been in the spotlight worldwide since 2000 , when it was recognised by the World Health Organization as a matter of public health concern. Both bullying perpetration and victimisation are associated with adverse mental health outcomes and social vulnerability in adult life. ${ }^{1}$ 
Literature reveals that bullying is documented in different countries independently of their geographical, socioeconomic or cultural characteristics. A cross-national study ${ }^{2}$ indicated that 8.6-45.2\% of children were frequently involved in school violence as victims, perpetrators or both. However, the prevalence of bullying and victimisation among countries varies; in Greece, reported rates of involvement in the phenomenon ranged from 26 to $41 \%$, much higher compared with other countries. ${ }^{2}$

The aim of this article is to picture school bullying and related policies in Greece in the context of increasing diversity and to review their evolution in the past decade.

\section{Bullying in Greek schools}

Greece is a south-eastern European country, located on the tip of the Balkan Peninsula. The problem of school bullying and victimisation seems to have started to concern Greek society later than other European countries. Related research has been small-scale, methodologically diverse and without any official institutional supervision, and associated literature was scarce until 2000; ${ }^{3}$ thus, drawing safe conclusions about the situation in Greece was difficult. In the past decade, the economic crisis has led to significant changes in the country's population composition. Greek society was believed to be rather traditional and homogeneous for a long period of time. Ethnocultural diversity in Greece began to increase since 1990, after the first massive settlement of citizens of the former USSR and economic immigrants from low-income countries of Eastern Europe. At present, Greece is also being forced to accept sweeping changes due to migration waves of asylum seekers from the Middle East. There are no official data about the precise number of refugee children in Greece nor the size of the population of ethnic, linguistic and religious minorities. ${ }^{4}$ It has been recently estimated that 18500 refugee and migrant children reside in Greece, ${ }^{5}$ a significant number of whom have enrolled in public education. ${ }^{6}$

National health planning, complying with the United Nations Convention on the Rights of the Child, has included reception and accommodation services for refugees, in order to enhance respect for 'otherness'. As far as educational policies are concerned, it is noteworthy that embracing children from ethnic minorities is hampered by language barriers and the difficulty of reliably assessing their academic needs. Nearly two decades ago, a national programme with international schools and reception classes set the aim of supporting ethnic minority children by providing a safe school milieu tailored to their special educational needs and this resulted in an increased enrolment of refugee and immigrant children in school (Greek Parliament Law 2413/96). These strategies targeted reducing social exclusion and preventing racist behaviour in the school environment.

Within the time frame of the recent economic crisis and the above-mentioned migration waves, the question of possible association of school multiculturalism with bullying behaviours was raised. Surveys conducted by the University Research Institute of Mental Health between 1998 and 2018 revealed that school bullying has significantly increased in the past decade compared with the early 2000s. Victimisation ranged between 19.1 and $28.9 \%$ of all school children, and being a bully was reported in $9.1 \%$ of these children in 2002, $15.8 \%$ in 2010 and $14.2 \%$ in 2018. ${ }^{7}$ According to a survey in six European countries (Greece, Italy, Bulgaria, Estonia, Latvia and Lithuania), about $42 \%$ of teachers believed that instances of bullying and violence in schools were often downplayed or covered up by parents or school staff, who denied involvement of their child or their school respectively. ${ }^{8}$

According to Stavrou et $\mathrm{al}^{7} 3.9 \%$ of adolescents in Greece reported being victimised because of their sexual identity, $2.8 \%$ because of their origin and $2.1 \%$ because of their family's socioeconomic status. The most frequent form of bullying was verbal violence, such as spreading false rumours and sexual insults. Boys reported more often experiencing physical violence and being insulted because of their ethnic identity or religion, whereas girls seemed to suffer mainly from false rumours.

\section{School bullying and minority identity}

Bullying behaviours are related to intolerance towards anything diverse or unfamiliar regarding norms, identities and attitudes; therefore, ethnicity may function as a status characteristic contributing to peer victimisation. ${ }^{9}$ This raises questions on whether discriminatory bullying may be attributed to the children's 'immigrant status' and be affected by the composition of the school population. ${ }^{10}$

A noteworthy example that has allowed the study of school bullying in relation to cultural identity in Greece is the geographical subdivision of Thrace. It is the north-eastern prefecture of the country, bordering Bulgaria and Turkey. Thrace's cultural diversity has been formed by various ethnolinguistic and religious groups over the years. Its population consists of (a) the Christian Orthodox population; (b) the Muslim minority, which is a dominant minority group, including the Pomaks and the Roma people; and (c) the descendants of Armenian refugees and expatriated Greeks from countries of the former Soviet republics settled in Thrace after 1990. ${ }^{11}$ All these cultural minorities are socially introverted and retain many of their customs. According to research on school bullying behaviours in Thrace, ${ }^{12}$ one in three secondary school students has been involved in bullying behaviours, nearly a quarter were identified as victims and one in six reported having bullied others. 
Students of minority status reported having experienced discriminatory victimisation more frequently compared with the majority group. School size was a crucial factor; schools with fewer students were less likely to record bullying incidents, compared with schools with a large student population. Additionally, both aggression and victimisation were more frequently observed when minority and majority students' groups were almost numerically equal. On the contrary, peer victimisation was less frequent in schools where the minority group was either outnumbered or predominant compared with the majority students. These results could be explained by Blalock's group threat theory, which posits that feelings of ethnic threat are more intense in contexts where the different ethnic groups are of roughly equal size. ${ }^{13}$

\section{School bullying and children's mental health}

Children and young people involved in bullying are very often engaged in risky behaviours, present with low academic achievement and experience mental health difficulties that accompany them into adulthood. ${ }^{14}$ Adolescents from ethnic minority groups in particular who were involved in bullying behaviours reported more internalising problems compared with uninvolved peers. ${ }^{12,15}$

More specifically, it has been noted that victims of bullying frequently suffer from anxiety, depression, social withdrawal and various psychosomatic complaints, whereas bullying perpetrators demonstrate high levels of externalising problems, such as aggression and rule violation. ${ }^{12,16}$ Children of dual status (bully/victim) seem to be the most vulnerable group, usually reporting low self-esteem, extremely high rates of depression and anxiety, and school maladaptation compared with other involved children. They also present with hyperactivity and impulsiveness and experience peer rejection. ${ }^{17}$

As a result, fear of school and truancy are more prevalent among students involved in bullying behaviours compared with unaffected peers. ${ }^{12,18}$

\section{The challenge for a national policy}

European countries have developed different strategies to target bullying. Many countries participate in international anti-bullying actions funded by the European Union (e.g. Ireland, Italy, Lithuania, Romania), while others have adopted integrated national policies implemented by their educational authorities (e.g. Bulgaria, France, Romania, the UK). Sweden, Belgium and Malta have also enacted anti-bullying laws to implement practices against school violence. ${ }^{19}$

In Greece, a national policy against bullying has been relatively recently adopted. In 2012, the Hellenic Ministry of Education formed an Observatory for the Prevention of School Violence and Bullying. It plans and coordinates the anti-bullying prevention strategy, mainly based on enhancing relative awareness among teachers and evaluating school programmes, with the aim of facilitating positive social interactions among all students. Furthermore, school counsellors, education directors and teachers were called to raise bullying mindfulness among students and invest time in extra-curricular activities. A telephone helpline has also been set up by a non-governmental organisation to provide confidential out-of-hours support, crisis resolution and health-specialist advice. Public opinion has been significantly sensitised thanks to parental psychoeducation. March 6 was established as a National Day of Action against School Violence.

Policies addressing the educational integration of migrant children and the management of cultural diversity include intercultural schools, reception classes, educational priority zones, amplifier tutorials and foreign schools. The ultimate goal is to prevent school violence, through social integration.

School bullying and its impact on mental health demands an interdisciplinary approach and public health initiatives, including culturally sensitive anti-bullying campaigns.

\section{Author contributions}

A.G. was responsible for literature screening and writing the manuscript. M.S. supervised the design and the writing of the manuscript. A.S. had responsibility for the structure of the manuscript, literature screening and writing the manuscript.

\section{Declaration of interest}

None.

ICMJE forms are in the supplementary material, available online at https://doi.org/10.1192/bji.2020.51.

\section{References}

1 Tsitsika AK, Barlou E, Andrie E, Dimitropoulou C, Tzavela EC, Janikian $\mathrm{M}$, et al Bullying behaviours in children and adolescents: "an ongoing story". Public Health Front 2014; 2: 7

2 Craig W, Harel-Fisch Y, Fogel-Grinvald H, Dostaler S, Hetland J, Simons-Morton B, et al A cross-national profile of bullying and victimization among adolescents in 40 countries. Int J Public Health 2009; 54: 216-24.

3 Andreou E. Bully/victim problems and their associations with psychological constructs in 8 to 12 year-old Greek school children. Aggress Behav 2000; 26: 49-56.

4 Fassmann H, Reeger U, Sievers W. Statistics and Reality: Concepts and Measurements of Migration in Europe. Amsterdam University Press, 2009.

5 National Center for Social Solidarity (EKKA). Situation Update: Unaccompanied Children in Greece, 29 February 2020. EKKA 2020. (https://www.unicef.org/eca/media/10856/file).

6 United Nations High Commissioner for Refugees (UNHCR), United Nations International Children's Emergency Fund (UNICEF), International Organization for Migration (IOM). Access to Education for Refugee and Migrant Children in Europe. UNHCR/UNICEF/IOM, 2019 (https://www.iom.int/sites/default/ files/press_release/file/access-to-education-for-refugee-children. pdf)

7 Stavrou M, Kanavou E, Fotiou A, Kokkevi A. Bullying among Adolescent Pupils in Greece (Short Report Series: Adolescents, Behaviours \& Health). University Mental Health, Neurosciences and Precision Medicine Research Institute 'Costas Stefanis', 2020. 
8 Smile of the Child. European Bullying Research. Project "Daphne": Europe's Antibullying Campaign (Final Report). Smile of the Child, 2012 (http://www.e-abc.eu/files/1/PDF/Research/ School_Bullying_eng.pdf).

9 Tsiantis J. Daphne program: Needs assessment and awareness raising programme for bullying in schools. Association for the Psychosocial Health of Children and Adolescents, 2008. Project no: JLS/DAP/2005-1/040/YG

10 Vervoort MH, Scholte RH, Overbeek GJ. Bullying and victimization among adolescents: the role of ethnicity and ethnic composition of school class. J Youth Adolesc 2010; 39: 1-11.

11 Eurostat Statistical books. People in the EU: Who Are We and How Do We Live? Publications Office of the European Union, 2015.

12 Serdari A, Gkouliama A, Tripsianis G, Proios H, Samakouri M. Bullying and minorities in secondary school students in Thrace-Greece. Am J Orthopsychiatry 2018; 88: 462-70.

13 Blalock HM. Toward a Theory of Minority-Group Relations. John Wiley \& Sons, 1967.

14 Forster M, Dyal SR, Baezconde-Garbanati L, Chou CP, Soto DW, Unger JB. Bullying victimization as a mediator of associations between cultural/familial variables, substance use and depressive symptoms among Hispanic Youth. Ethn Health 2013; 18: $415-32$

15 Leiner M, Dwivedi AK, Villanos MT, Singh N, Blunk D, Peinado J. Psychosocial profile of bullies, victims, and bully-victims: a cross-sectional study. Front Pediatr 2014; 2: 1.

16 Jiang D, Walsh M, Augimeri LK. The linkage between childhood bullying behaviour and future offending. Crim Behav Ment Health 2011; 21: 128-35.

17 Hong JS, Davis JP, Sterzing PR, Yoon J, Choi S, Smith DC A conceptual framework for understanding the association between school bullying victimization and substance misuse. Am J Orthopsychiatry 2014; 84: 696-10.

Cook CR, Williams KR, Guerra N, Kim TE, Sadek S. Predictors of bullying and victimization in childhood and adolescence: a meta-analytic investigation. Sch Psychol 2010; 25: 65-83.

19 Artinopoulou V, Michael I. EAN Strategy Position Paper. European Antibullying Network, 2014. (https://www.academia. edu/9670175/Artinopoulou_V_and_Michael_ I_Eds_2014_EAN_Strategy_Position_Paper)

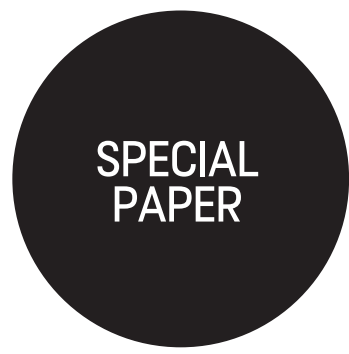

\title{
Suicide among Ugandan university students: evidence from media reports for $2010-2020$
}

\author{
Mark Mohan Kaggwa, ${ }^{1} \odot$ Moses Muwanguzi, ${ }^{2}$ Elicana Nduhuura, ${ }^{3}$ \\ Jonathan Kajjimu, ${ }^{4}$ Innocent Arinaitwe, ${ }^{5}$ Moses Kule, ${ }^{6}$ Sarah Maria Najjuka ${ }^{7}$ \\ and Godfrey Zari Rukundo ${ }^{8}$
}

'Postgraduate Student Department of Psychiatry, Faculty of Medicine, Mbarara University of Science and Technology, Uganda; and African Centre for Sulcide Prevention and ention and Email: kmarkmohan@gmail.com 2Undergraduate Medical Student, Faculty of Medicine, Mbarara University of Science and Technology, Uganda

3Undergraduate Medical Student, Faculty of Medicine, Mbarara University of Science and Technology, Uganda

Undergraduate Medical Student Faculty of Medicine, Mbarara University of Science and Technology, Uganda

SUndergraduate Medical Student, Faculty of Medicine, Mbarara University of Science and Technology, Uganda

Undergraduate Medical Student Faculty of Medicine, Mbarara University of Science and Technology, Uganda

${ }^{7}$ Medical Student, College of Health Sciences, Makerere University, Kampala, Uganda

${ }^{8}$ Senior Lecturer, Department of Psychiatry, Faculty of Medicine Mbarara University of Science
University students are in transition to adulthood and face multiple challenges that may lead to suicide. They are reported to have a higher risk of suicide by the World Health Organization. As there is no national suicide database in Uganda, we analysed student suicide using the press/media reports of suicides published between 2010 and 2020 . A total of deaths by 23 suicide were identified: 19 were males, relationship problems were the main suicide reason $(n=6)$ and hanging was the most frequently used suicide method $(n=7)$. A strategic intervention to tackle suicide risk among university students is warranted.

Suicide is a global health concern, with $79 \%$ of the annual incidence occurring in low- and middleincome countries. ${ }^{1}$ However, suicide remains illegal in many African countries, including Uganda, and no suicide attempter would dare not to complete it for fear of the repercussions attached. $^{2}$ Although suicide rates in Uganda decreased from 15.91 per 100000 population in 2000 to 9.9 per 100000 in $2017,,^{3}$ the rates remained highest among the youth (approximately 700000 are university students). University students are transitioning from adolescence to adulthood, a stage associated with many stressors (physical, psychological, social and spiritual) that overpower many, leading to suicide. Previous studies have demonstrated high numbers of suicides among university students. ${ }^{4-6}$ The year 2020 came with multiple unexpected challenges due to the COVID-19 pandemic that may have put many at risk of dying by suicide. ${ }^{7}$ Looking at past suicide cases may give us an insight into what to expect for better preparation and interventions. With no central database for suicide in Uganda, literature about suicide among university students is limited. This paper describes a study of press/media reports about suicide, its risk factors and the commonly used methods among university students in Uganda. We adopted an approach used by countries without suicide databases. $^{5}$

\section{Method}

Data collected were from various Ugandan media reports of university students who completed 